\title{
Research on Teaching Reform and Innovation of Chinese Painting Course in Ceramic Art Design
}

\author{
Bao Chen ${ }^{1, a}$, Sheng $\mathrm{Bi}^{2, b}$, Hua Zou ${ }^{3, \mathrm{c}}$ and Shanshan $\mathrm{Ye}^{4, \mathrm{~d}}$ \\ ${ }^{1}$ College of Technology and Art, Jingdezhen Ceramic University, \\ ${ }^{2}$ Jingdezhen Ceramic University Ceramic Art Department, Jingdezhen Jiangxi Province 333403 \\ 5126571@qq.com
}

Keywords: Ceramic Art Design; Chinese Painting Course; Teaching Method; Innovation Method

\begin{abstract}
Based on the characteristics of Chinese birds and flowers painting, this article aims to cultivate the goal of ceramic art design talents. Through certain research and practice, it tries to explore the innovative teaching methods of Chinese flower and bird painting courses in ceramic art design, and guides college students to perceive and to discovering the cultural connotation of traditional Chinese painting art, researching and mining the performance elements suitable for applying to ceramic design.

The Chinese painting curriculum is a very important basic course in art institutes in the country, or in fine arts teaching in many universities. It is also generally used as an introductory course in learning Chinese painting. In the ceramic art design majors of major art colleges in Jingdezhen, Chinese painting has long been considered as a required art major basic course. The ceramic art design major has been set up in some domestic universities, but it is not universal in comparison with other majors. It attaches great importance to the study and research of traditional Chinese painting techniques and is different from the pure Chinese painting major. It is to train professional designers who possess traditional cultural roots, master certain Chinese painting techniques and are able to explore and think and create ceramic works. As one of the basic courses, Chinese painting is set up more reasonably, which helps guide students to master and improve their artistic appreciation ability and lays a solid foundation for follow-up ceramic design professional courses.
\end{abstract}

\section{Problems in the Course of Ceramic Art Design Professional Chinese Painting}

Divorces from professional training goals. In setting up Chinese painting courses in non-painting majors, its emphasis is very different from that of painting majors. The Chinese painting course of ceramic art design major belongs to the category of basic courses. The basic course teaching has a certain professional orientation, and it is necessary to reasonably arrange and set course content in accordance with professional training objectives. The course schedule for Chinese painting arts in ceramic art design is relatively short, and it is easy to move toward simple training in the teaching of the course, which is out of touch with the training goal of the ceramic design profession. In practice teaching, simply teaching techniques is far from enough. Even if the techniques are mastered well, it may not be able to apply the traditional Chinese painting elements to design. The simple technique of copying does not enable students to gain an understanding of the traditional cultural and artistic connotations of our country, and it is even more difficult to promote the cultivation of creative thinking and thinking about the localization of design.

The simplification and superficiality of teaching. The combination of the Chinese painting curriculum and the training objectives of the ceramic design profession is a process that requires constant exploration and practice. In this process, there is inevitably a problem of unilateral and surface teaching. Mainly reflected in the following: First, in the short-term teaching process, teachers only allow students to try Chinese painting technique exercises, or even a certain kind of technique exercises. They do not guide college students to understand and appreciate the connotation of Chinese art. Nor do they tap into and find the breakthrough point of our country's culture and design. The second is the lack of practical exercises combining design and Chinese painting art in teaching content, which has a certain relationship with the academic background of 
Chinese traditional painting teachers. The third is to ignore the procedural nature of teaching, focusing only on the results. The teaching of Chinese flower and bird painting courses is a complex and regular process. The teaching of this course can hardly see obvious results in a short period of time. Therefore, the teachers easily breed the idea of eagerness of quick success and instant profit, blindly simplifying the teaching just to achieve the obvious results of teaching, which is easy for students to lose interest and confidence in the learning of Chinese painting. Compared to the results, the process of university students' learning and exploration is even more important. In this process, college students' attention to traditional Chinese culture, as well as thinking and practice of design and traditional art will form a habit, which will have a beneficial influence on the future design.

University students' deviations from design concepts. Integrating the excellent design of national culture requires the designer to have a deeper exploration of his own culture. From the state of college students, they pay more attention to the modern design concepts and methods from the perspective of internationalization. There is little thinking about the integration of ethnic art and modern design. Little is known about traditional Chinese cultural theory, and even the theories of traditional culture of our country are considered obsolete. In addition, most college students do not have enough knowledge of the course itself before attending class. They think that this is a purely technical course and has little connection with their professional study. On the other hand, college students have a strong ability to comprehend new ideas and methods. If our teaching can adapt to the needs of modern art design concepts, we must go beyond a single teaching model and guide the university students in the continuous practice and exploration to explore the artistic design language with the cultural atmosphere of the nationality. The views of the university students on our traditional cultural theory will change.

\section{The Teaching Reform and Innovation Approach of Chinese Painting Course in Ceramic Art Major}

Focus on teaching philosophy and teaching goals. The teaching of Chinese painting in the ceramic art design profession and the one in pure art have great differences in teaching philosophy and training objectives. The pure art Chinese painting teaching has a large system. The Chinese painting teaching in the ceramic art design major not only needs to practice techniques, but also rely on our artistic resources to train college students in visual thinking. Therefore, the purpose of the teaching of ceramic art design major should include three aspects: The first is to cultivate college students' comprehensive appreciation of Chinese painting arts. For a design student, it is more important to have a good ability to comprehensively appreciate the art of Chinese painting than to master some techniques. College students may not be able to create works of a certain height, but they must have a good appreciation of our country's painting art, be able to research and explore, extend and break through the elements of traditional Chinese art, and apply it to design rationally. Traditional culture can be reflected in the design works in explicit or implicit language, symbol or spirit, which is to give the work a unique Chinese cultural imprint. Without the appreciation of traditional art, these elements cannot be freely applied to design. The second is to guide college students to discover and excavate the graphic language, cultural details, and internal emotions of Chinese art, and apply it to design. Traditional Chinese art provides rich resources for modern design and has great visual research value. As a designer, it is necessary to carry out new discoveries and excavations of traditional Chinese cultural elements. Chinese painting courses of art design major must guide students to perceive, explore and discover the connotations of traditional Chinese art, and find elements that are applicable to design. Third, through exploration and practical exercises, students have been concerned about their own cultural environment and living conditions.

Arrange the content of the course reasonably to realize the organic integration of teaching. The first is the study of theory and the appreciation of classic works. First of all, college students need to master the basic theoretical knowledge of Chinese painting, including the characteristics and classification of Chinese painting, the similarities and differences between Chinese and Western paintings, the representative painters and their works, and creative styles. The teaching methods are mainly taught by teachers. Through studying, college students will have a broad and 
basic understanding of the basic theories of Chinese painting. However, the theoretical system of Chinese painting is very large, and the amount of knowledge that college students receive in class is very limited. This can encourage college students to conduct independent research on some in-depth theories, further mobilize the students' interest in learning, and combine practice with self-study. Secondly, for college students majoring in art and design, they may not be able to reach a certain height in technique within a short time, but they should have the ability to appreciate Chinese painting. Only with the basic appreciation ability can we understand how to tap the good visual language in Chinese painting art and use it for ourselves. The second is experience and feelings. At this stage, some copying of Chinese paintings is mainly performed. The works of ancient and contemporary masters can be diversified in terms of form, theme and style. Before copying, teachers need to explain to the students about the copying and some knowledge related to the works, such as the style of the work, the painter's style and the background of the time, the basic steps and methods of painting, and the characteristics of the painting materials. Under this premise, should students start copying.

Change classroom teaching mode and strengthen modern education technology. The combination of modern technology and teaching is an inevitable trend of modern teaching methods. In the course of cultivating and improving students' Chinese painting literacy, students are exposed to a large number of high-level Chinese painting works and familiar with some of the expressions of Chinese traditional paintings. This is an important way to enrich students' image accumulation. Guide students to appreciate the traditional painting education, combine rationality and sensibility, avoid the previous rigid theoretical rigid classroom teaching, use new technology to learn Chinese traditional painting, and improve students' own level. The use of Internet electronic equipment in the classroom will help students explore the traditional Chinese painting art. The Song and Yuan Dynasties were the heyday of Chinese painting history. The school could purchase high-definition picture resources or high-reproducible Chinese painting reproductions of Chinese paintings. Compared with the traditional Linyi teaching materials, the advantage was that the electronic resources had a magnifying function and could show the fine detail of ancient paintings. High-definition copy is from the size, color, material to the sense of volume, strokes, replicas show the original charm in no time to achieve the epoch-making copy effect. In the past, students were only able to watch their original works in a limited period of time while museums and galleries were open. They can now use the high-definition prints to carefully figure out how to use the pens to pick up, press, pause, frustrate, lay, hide, hide, and reveal and to use ink's signs of dryness, wetness, darkness, and lightness, and use weak colors to analyze and study, in order to grasp the essence of the picture. Being able to perceive the state and connotation of the work itself in a closer and more direct way will help students better study Chinese traditional painting and understand the essence of Chinese painting. High-tech applications and traditional culture classrooms can not only greatly increase the classroom atmosphere, effectively improve the quality of the subject's teaching, but also enhance the ability of college students to boldly explore and differentiate Chinese art.

\section{Summary}

The establishment of a Chinese painting course in the ceramic art design major should always be closely linked to professional training objectives so that students can effectively master Chinese painting techniques and guide students to explore artistic design languages that have a national cultural atmosphere. In the teaching process, the teaching model of teaching, research, and practice is used consistently, and organic integration and deep development of the three are achieved. To adapt the reform of ceramic art design Chinese painting courses to the needs of professional training, and to better integrate into the mainstream of local college teaching reform.

\section{References}

[1] Y.M.Gao The Necessity of Setting Up Chinese Painting Courses for Art Design Majors in Colleges and Universities. J. Art and Design(2008). 6 
[2] H.Y.Zhang The Role of Chinese Painting in Art Design Education. J. Journal of Hebei Normal University(2009)

[3] The Teaching Reform of Chinese Painting Course in Art Design Major. J. Journal of Tianjin city manager College 6(2012.12)

[4] J.Chen The influence of modern science and technology on the innovation of Chinese painting. Guide, science and Education Forum

[5] Peng L. Cost heterogeneity and peak prediction in collective actions [J]. Expert Systems With Applications, 2017, 79: 130-139. 